\title{
Gut
}

Editorial

\section{Gut moves towards the 3rd millennium}

It was with some trepidation but undeniable enthusiasm that I took over the editorship of Gut from Bob Allan. Gut flourished under his editorship and is now one of the most respected and widely read international journals of gastroenterology and hepatology. Before finally deciding on a new management structure for the journal, I took soundings from other editors of specialist journals and had the privilege of spending two days in the editorial office of Gastroenterology with Nick LaRusso and colleagues. This convinced me that my proposed change of recruiting a team of associate editors was unquestionably the right way forward. This structure brings a vital breadth to the editorial process and a corporate spirit to what otherwise might be a lonely and isolated pursuit. The associate editors (Michael Arthur, John Calam, Roger Chapman, Ian Forgacs, Michael Kamm, and Tom MacDonald) are all young (relatively), active, and well respected clinical and/or basic scientists, each bringing special expertise to the editorial committee. I and the associate editors will handle manuscripts within our area of expertise, selecting reviewers and feeding back reviewers' comments to authors. We meet every two weeks to determine the fate of manuscripts submitted to the journal. We feel confident that this structure will increase confidence in the decision making process, improve the quality of papers published in Gut, and increase the standing of the journal internationally.

We are keen to reduce still further the time between receipt of a manuscript and publication. Once the new editorial process is in place, we aim to achieve publication within four to five months. This will be achieved by checking that potential reviewers are able to complete their review within 21 days before sending out the manuscript, by reducing delays within the office to the absolute minimum, and ensuring that the editor and associate editors make the first decision on the fate of a manuscript immediately the reviewers' comments are received. To ensure that we achieve these objectives we have taken on an additional editorial assistant, Julia Neary who will assist our technical editor, Jackie Foulds and editorial assistant, Michelle Dimler. So far we have been encouraged by the changes that we have made to the process, but only time will tell whether we are able to achieve these new objectives.

The journal continues to carry high quality clinical and laboratory based monographs on topics in gastroenterology and hepatology, but we are proposing to add some new sections to the journal At the front we will continue to publish one or two leading articles each month but in addition we will commission highly focused short review articles (3000 words) on fast moving topics of clinical and scientific interest. At the back of the journal we will publish short commentaries on papers of special interest published in the same issue of the journal, which will be invited at the time a key paper is accepted for publication. In some instances we might invite an individual who acted as a reviewer of the manuscript, while for others we may invite an expert in the field who might have views that are at variance with the newly published findings. We hope that this section will encourage debate and enhance the correspondence columns of the journal. We also propose to introduce a section on International News in which there will be a regular contribution from the United European Gastroenterology Federation; we anticipate that this will enhance the contribution of Gut to European gastroenterology. Ian Forgacs will play a lead role in driving these new sections, guided by the specialist expertise of the associate editors and myself. Overall the editors will be looking to reduce the length of individual manuscripts and guidelines for the preparation of manuscripts are included in this issue of the journal.

We are committed to continue the internationalisation of Gut and plan to progressively increase the involvement of gastroenterologists and hepatologists around the world in the editorial management of the journal. To begin this process we have dis-established the Editorial Board and the International Advisory Board, which are now reconstituted as a single Editorial Board with representation across the continents (see inside front cover). This move reinforces our commitment to continue the internationalisation of Gut and to encourage the involvement of colleagues outside the UK in the management of the journal. Bob Allan established an extensive international database of reviewers and this is currently being updated and extended. The editors will have no contact with manuscripts submitted to the journal from their own institution and thus we will be calling on members of the Editorial Board to act as guest editors for these manuscripts. With fax, E-Mail, and teleconference facilities I envisage that it shall be possible to recruit associate editors from Europe and beyond within the foreseeable future.

Michael Farthing May 1996 